\title{
Estimating some hydrophysical properties of soil using mathematical modeling
}

\author{
Vitaly Terleev ${ }^{1}$, Wilfried Mirschel $^{2}$, Aleksandr Nikonorov $^{1, * *}$, Roman Ginevsky ${ }^{1}$, Viktor \\ Lazarev $^{1}$, Issa Togo ${ }^{1}$, Alex Topaj ${ }^{3}$, Kirill Moiseev ${ }^{3}$, Dmitry Shishov $^{4}$, Aleksandr \\ Melnichuk ${ }^{5}$, and Ielizaveta Dunaieva ${ }^{6}$
}

\footnotetext{
${ }^{1}$ Peter the Great St.Petersburg Polytechnic University, Polytechnicheskaya, 29, St. Petersburg, 195251, Russia ${ }^{2}$ Leibniz-Centre for Agricultural Landscape Research, Eberswalder Straße 84, Müncheberg, 15374, Germany ${ }^{3}$ Agrophysical Research Institute, Grazhdanskii pr., 14, St. Petersburg, 195220, Russia ${ }^{4}$ St.Petersburg State Agrarian University, Peterburgskoye shosse, 2, St. Petersburg-Pushkin, 196601, Russia ${ }^{5}$ V.I.Vernadsky Crimean Federal University, Vernadskogo pr., 4, Simferopol, Crimea, 295007, Russia ${ }^{6}$ Federal State Budget Scientific Institution «Research Institute of Agriculture of Crimea», Kievskaya, 150, Simferopol, Crimea, 295453, Russia
}

\begin{abstract}
At substantiating land amelioration and land management designs, as well as during periods of operation and reconstruction of water facilities, information support plays an important role in relation to the hydrophysical properties of soil. Effective implementation of this support faces a number of challenges. Such problems include the very high laboriousness of carrying out the corresponding engineering surveys and laboratory studies. In this regard, the methods of indirect estimating the hydrophysical properties, the measurement of which requires considerable labor, are very in demand for land amelioration and land management practices. An equally acute problem is the problem of the functional representation of the coefficients of the Richards equation, which is widely used in engineering-hydrological calculations. The paper suggests: 1) the original method for assessment of the ratio of the values of the hydraulic conductivity function of soil to the moisture filtration coefficient using data from direct measurements of the water-retention capacity of soil carried out according to the standard procedure; 2 ) the mathematical model describing the hydrophysical properties of soil, and the system of functions with interpreted parameters that physically adequately describe the coefficients of the Richards equation. In carrying out the study, data on soils of different texture were used. A sufficiently low error in the dot approximation (fittingprocedure) of the experimental data confirms the physical adequacy of the proposed system that includes the functions describing the coefficients of the Richards equation.
\end{abstract}

\footnotetext{
*Corresponding author: coolhabit@yandex.ru
} 


\section{Introduction}

In the construction industry, an important role is played by engineering surveys conducted to study the hydrological conditions of the soils of the erection of buildings and structures sites. In the period of operation and reconstruction of construction sites, data on these conditions are also required. Among all the variety of construction objects, such data are of greatest importance for hydraulic engineering structures, and, first of all, for irrigation and drainage systems. Moreover, information about the hydrological conditions of the soils is very relevant even in the period of operation and reconstruction of these systems.

The hydrological conditions of the soils are determined by the peculiarities of the terrain climate, and by the hydrophysical properties of the soils. The most important hydrophysical properties of soils include water-retention capacity and hydraulic conductivity. These properties as well as data on the groundwater level are taken into account in the design of drainage systems and the development of technologies for managing the water regime of the root layer of the soil under planting of crops, as well as in calculating irrigation rates in irrigation. The Richards equation is used to describe the dynamics of soil moisture [1]. This equation relates to a family of partial differential equations of parabolic type with variable coefficients. These coefficients describe the differential moisture capacity and hydraulic conductivity of the soil continuum stratum. The independent variables of the Richards equation are the spatial coordinates of the observation point of the moisture state (in the onedimensional case, the depth of the calculated layer) and time. The dependent variable is the capillary pressure (capillary-sorption potential) of moisture. Essentially, the search for a solution to this equation is reduced to a functional representation of these coefficients in the form of continuous dependencies on the capillary moisture pressure. The primary function of the differential moisture capacity is by definition a function of the integral moisture capacity, which describes the water-retention capacity of the soil continuum stratum as a relationship between the volumetric water content and the capillary moisture pressure of the calculated layer. The motivation for this research is due to the fact that to date there has not been offered an exhaustive theoretical justification for the considered dependencies on the basis of fundamental physical concepts [2]. Typically, the relationship between volumetric water content and hydraulic conductivity of capillary moisture pressure is described by empirical formulas that approximate point data of direct measurements with some error. With this approach, two problems inevitably arise. The first problem is the high laboriousness of conducting direct measurements. The second problem is the following: if in the calculation of the coefficient of the Richards equation that describes the differential moisture capacity, the operation of differentiating the approximation of the function of the integral moisture capacity is applied, then significant errors may arise. This is explained by the fact that this operation is (by definition) unstable with respect to approximations. In other words, differentiating the empirical dependence approximating the points on the water-retention capacity curve can lead to a result that deviates markedly from the differential moisture capacity curve. The presence of variable coefficients in the Richards equation does not allow obtaining its analytical solution. Therefore, numerical methods with iterative procedures are used to find the solution of this equation. The use of iterations inevitably leads to a multiplication of the error in the results of calculations.

The solution of these two problems is seen in the development of a physically adequate mathematical model of the hydrophysical properties of soil and the description of the differential water capacity, water-retention capacity and hydraulic conductivity of soil by a system of functions with common parameters. The purpose of this study is to analyze the feasibility of applying hydrophysical functions to assess the hydraulic conductivity of soil in the design, use or reconstruction of irrigation and drainage systems based on data on the water-retention capacity of soil, as well as data on the moisture filtration coefficient. The task 
of the study is a comparative analysis of three systems of hydrophysical functions using the criterion of the error in predicting the hydraulic conductivity of unsaturated soil according to the data on the water-retention capacity of the soil and the moisture filtration coefficient.

The objects of the study are selected soils of different granulometric compositions (texture), the data on which are borrowed from literature sources [3]. This choice of data is conditioned by the authors desire to maximally objectively identify the advantages and disadvantages of the hydrophysical functions used in the study, as well as the possibility of an independent examination of the results obtained in this study. During the research, methods of mathematical modeling and statistical estimation are used.

\section{Materials and methods}

To calculate the ratio of the function of hydraulic conductivity of the soil $k(\mathrm{~cm} \cdot \mathrm{c}-1)$ to the moisture filtration coefficient $k_{S}(\mathrm{~cm} \cdot \mathrm{c}-1)$ Mualem formula is used [4]:

$$
\frac{k}{k_{S}}=\sqrt{S_{e}}\left(\int_{0}^{S_{e}} \frac{d x}{\psi(x)} / \int_{0}^{1} \frac{d x}{\psi(x)}\right)^{2}
$$

where $S_{e}=\left(\theta-\theta_{R}\right) /\left(\theta_{S}-\theta_{R}\right)$ - effective moisture saturation of soil; $\theta(\mathrm{cm} 3 \cdot \mathrm{cm}-3)-$ volumetric water content in the soil; $\theta_{S}(\mathrm{~cm} 3 \cdot \mathrm{cm}-3)$ - saturated volumetric water content in the soil; $\theta_{R}(\mathrm{~cm} 3 \cdot \mathrm{cm}-3)$ - residual volumetric water content corresponding to the minimum specific volume of moisture as a fluid in the soil; $\psi$ ( $\mathrm{cm} \mathrm{H} 2 \mathrm{O})$ - capillary moisture pressure.

To describe the water-retention capacity and hydraulic conductivity of the soil, a system of hydrophysical functions with common parameters, Van Genuchten proposed to substitute in dependence $\theta(\psi)$ to the formula (1) in the form of:

$$
S_{e}=\left[\begin{array}{l}
\left(1+(-\alpha \psi)^{n}\right)^{-m}, \psi<0 ; \\
1, \psi \geq 0,
\end{array}\right.
$$

where: $\alpha$ (m H2O-1), $n$ and $m$-empirical parameters [5].

When $m=1$ function (2) is reduced to the models of predecessors [6-8], therefore the use of formula (1) runs into a computational difficulty. However when $m=1-1 / n \quad(n>1)$ function (1) admits an analytical calculation:

$$
\frac{k}{k_{S}}=\left[\begin{array}{l}
\sqrt{S_{e}}\left(1-\left(1-S_{e}^{1 / m}\right)^{m}\right)^{2}=\left(1+(-\alpha \psi)^{n}\right)^{-m / 2}\left(1-\left(1-\left(1+(-\alpha \psi)^{n}\right)^{-1}\right)^{m}\right)^{2}, \psi<0 \\
1, \psi \geq 0
\end{array}\right.
$$

The approach for hydrophysical calculation using relations (2) and (3) has the name of Mualem-Van Genuchten method, which is currently being used very well. At the same time, this method has a relatively high error for the soil of a heavy granulometric composition, as evidenced by the result obtained by Van Genuchten for Beit Netofa clay [5]. Relations (1) and (2) form a system of soil-hydrophysical functions\#1.

In the proposed approach by Kosugi describing the soil water-retention capacity, the concepts of soil as a capillary-porous media are used, and the formula of Mualem $(1)[9,10]$ are also used to calculate $k / k_{S}$. Common parameters for functions $\theta(\psi)$ and $k(\psi)$ have 
the meaning of statistics of the lognormal distribution of the capillary soil pore radii. In the papers $[11,12]$ Kosugi's ideas are developed and a system of soil-hydrophysical functions \#2 are described. The functions forming this system are represented in the following form:

$$
\begin{gathered}
S_{e}=\left[\begin{array}{l}
\left(1+\left(-\alpha\left(\psi-\psi_{e}\right)\right)^{n}\right)^{-1}, \psi<\psi_{e} \\
1, \psi \geq \psi_{e}
\end{array}\right. \\
\frac{k}{k_{S}}=\left[\begin{array}{l}
\frac{1}{4 \sqrt{2}} \sqrt{\operatorname{erfc}\left(\frac{n \sqrt{\pi}}{4} \ln \left(-\alpha\left(\psi-\psi_{e}\right)\right)+\frac{2}{n \sqrt{\pi}}\right)}\left(\operatorname{erfc}\left(\frac{n \sqrt{\pi}}{4} \ln \left(-\alpha\left(\psi-\psi_{e}\right)\right)+\frac{2}{n \sqrt{\pi}}\right)\right)^{2}, \psi<\psi_{e} \\
1, \psi \geq \psi_{e},
\end{array}\right.
\end{gathered}
$$

where: $\quad \operatorname{erfc}(x)=1-\frac{2}{\sqrt{\pi}} \int_{0}^{x} \exp \left(-t^{2}\right) d t \quad$ - complementary error function; $n>0$, $\alpha=-1 /\left(\psi_{0}-\psi_{e}\right)(\mathrm{cm} \mathrm{H} 2 \mathrm{O}-1) \quad, \quad \psi_{e} \quad(\mathrm{~cm} \mathrm{H} 2 \mathrm{O}), \quad \psi_{0}(\mathrm{~cm} \mathrm{H} 2 \mathrm{O})<\psi_{e}-\quad$ interpreted parameters (taking into account hysteresis for desorption branches $\psi_{e}<0$; for sorption branches $\left.\psi_{e} \geq 0\right)$.

In the paper [12] continuous approximations of the relations (4) and (5) in the class of elementary functions are proposed using the simplified Winitzky formula [13]. Here the relations (4) and (5) are respectively transformed to the form:

$$
\begin{gathered}
S_{e}=\left[\begin{array}{l}
\left(1+\left(-\alpha\left(\psi-\psi_{e}\right)\right)^{n}\right)^{-1}, \psi<\psi_{e} ; \\
1, \psi \geq \psi_{e}
\end{array}\right. \\
\frac{k}{k_{S}}=\left[\begin{array}{l}
\left(1+\left(-\alpha\left(\psi-\psi_{e}\right)\right)^{n}\right)^{-1 / 2}\left(1+\left(-\alpha\left(\psi-\psi_{e}\right)\right)^{n} \exp \left(\frac{8}{n \pi}\right)\right)^{-2}, \psi<\psi_{e} ; \\
1, \psi \geq \psi_{e}
\end{array}\right.
\end{gathered}
$$

Relations (6) and (7) form a system of soil-hydrophysical functions \#3. When $\psi_{e}=0$ function (6) reduces to the model proposed by Haverkamp and other predecessors [6-8]. The parameters of functions (4)-(7) can be estimated from the physical and statistical indicators of the soil. Parameter $\psi_{0}$ characterizes the capillary moisture pressure, which corresponds to the value of volumetric water content $\theta_{0}$, equal to half-sum $\theta_{R}$ and $\theta_{S}$. Parameter $\theta_{R}$ can be estimated by the value of soil maximum hygroscopy. Parameter $\theta_{S}$ can be calculated by the formula: $\theta_{S}=1-\rho_{b} / \rho_{p}$, where $\rho_{b}$ - soil bulk density; $\rho_{p}-$ soil particle density. Physical and statistical meaning of the parameters $n$ and $\alpha$ is seen from formulas: $n=4 /(\sigma \sqrt{2 \pi}), \alpha=r_{\max } r_{0} /\left(\beta\left(r_{\max }-r_{o}\right)\right)$ or $\alpha=r_{o} / \beta$ when $r_{\max } \gg r_{0}$. In these formulas: $r_{0}$ - pore radii, which corresponds to the most probable value of a normally distributed random variable $\ln \left(\left(r-r_{\min }\right) /\left(r_{\max }-r\right)\right)$ with standard deviation $\sigma ; r$ - capillary pore radius; $r_{\max }$ - radius of the largest pore; $r_{\min }$ - radius of the smallest pore; $\beta$-dimensional constant in Laplace's law $\psi-\psi_{e}=-\beta / r$, which is calculated by the formula $\beta=2 \gamma \cos \varphi /\left(g \rho_{W}\right)$, where $\gamma-$ coefficient of surface tension of moisture at the boundary with air, $\varphi$ - the contact angle of the surface of soil particles, $g$ - gravity acceleration, $\rho_{W}-$ 
density of the water. An estimate of this constant is known: $\beta=0.149 \mathrm{~cm}^{2}[6,14-16]$. Parameter $\psi_{e}$ characterizes the boundary value of the interval $\psi$ on the isotherm of soil drying, which corresponds to the entrance pressure of air [17].

\section{Results}

Here are the results of a comparative analysis of the three systems of hydrophysical functions using the error criterion for predicting the hydraulic conductivity of unsaturated soil according to data on the soil water-retention capacity and the moisture filtration coefficient. Literature data for eight soils of different granulometric compositions were used. Van Genuchten investigated the Beit Netofa clay, along with the other four soils with lighter granulometric compositions [5]. For these four soils, Van Genuchten obtained quite satisfactory results, but for the Beit Netofa clay from the Mualem catalog [3], the result was rather doubtful. That is why; this article also considers this soil. In addition, data on seven soils with lighter granulometric compositions were also used from the Mualem catalog [3] and which were not considered in Van Genuchten's article [5].

In the Figures 1-8 solid curves show the results of a dot approximation of the experimental data on the soil water-retention capacity, as well as predictions of the relative hydraulic conductivity $k / k_{S}$ unsaturated soil. The red curves are corresponding to the system\#1 and have been drawn using the Van Genuchten soil water-retention capacity function (WRC-VG) and the Mualem-Van Genuchten soil hydraulic conductivity function (HC-MVG). The blue curves are corresponding to system\#2 and have been drawn using the improved Kosugi soil water-retention capacity function (WRC-K+) and the improved Mualem-Kosugi soil hydraulic conductivity function $(\mathrm{HC}-\mathrm{MK}+)$. The green curves are corresponding to the system\#3 and have been drawn using the improved Haverkamp of the soil water-retention capacity function $(\mathrm{WRC}-\mathrm{H}+$ ) and the Mualem-Terleev soil hydraulic conductivity function (HC-MT). In the Figures 1-8 black circles represent experimental data of water-retention capacity, and white squares are the relative hydraulic conductivity of the investigated soils.

In the Table 1, the values of the parameters for each of the three compared systems of hydrophysical soil functions are shown. In the Table 2, the errors of the dot approximation of the experimental data on the soil water-retention capacity, as well as the predictions of the relative hydraulic conductivity $k / k_{S}$ unsaturated soils for the three compared systems of soil-hydrophysical functions are shown. The boldface indicates minimum errors.

Data about soil chemical properties was determined for fine earth (Table 2). Obtained data indicated that soils are characterized by following features. Soils were characterized principally by strongly acidic ( $\mathrm{pH}$ 5.1-5.5) conditions in Kharsaim, slightly acidic and almost neutral (pH 6.1-6.9) conditions in Aksarka, Labytnangi and Murmansk (Table 2). The pH values were characterized mostly as strongly acidic $(\mathrm{pH} 4.7-5.1)$ for Salekhard and Kharp key plots. Particle size distribution analysis showed predominance of silt fraction in soils of key plots located on the river terraces of $\mathrm{Ob}^{\prime}$ River (Aksarka, Kharsaim) and predominance of sand fraction in soils of the other key plots (Salekhard, Labytnangi, Kharp, Murmansk) (Table 2). The total organic carbon content in studied soil samples showed relatively high variability (values ranged between $0.19 \%$ and $14.58 \%$ ). It might be caused by high heterogeneity of soil material in studied technosoils due to the mixing caused by human activity. 

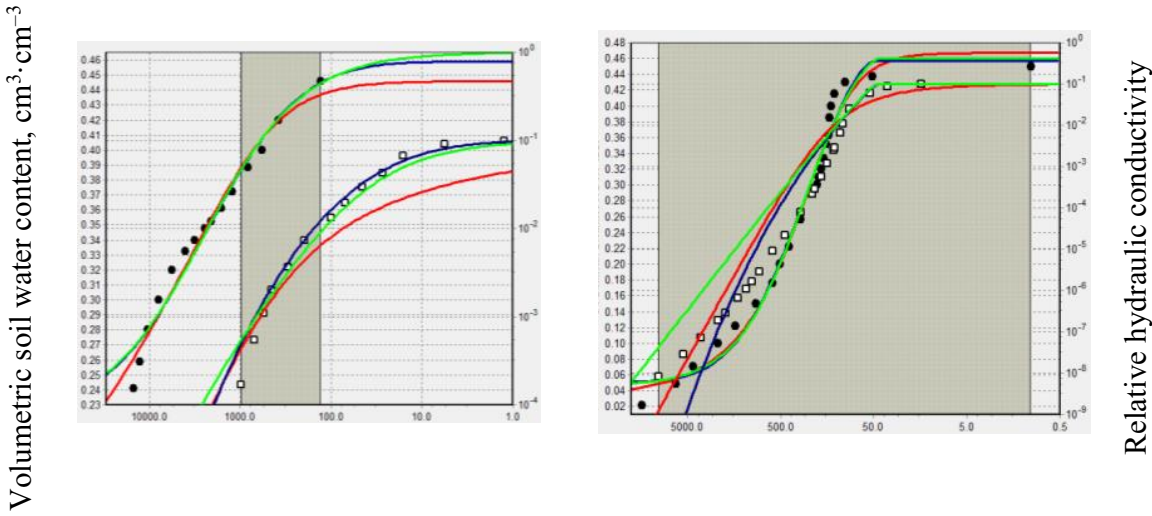

Capillary pressure of moisture (abs. value), $\mathrm{cm} \mathrm{H}_{2} \mathrm{O}$

Fig. 1. «1006 Beit Netofa clay».

Fig. 2. «3405 Indio loam».
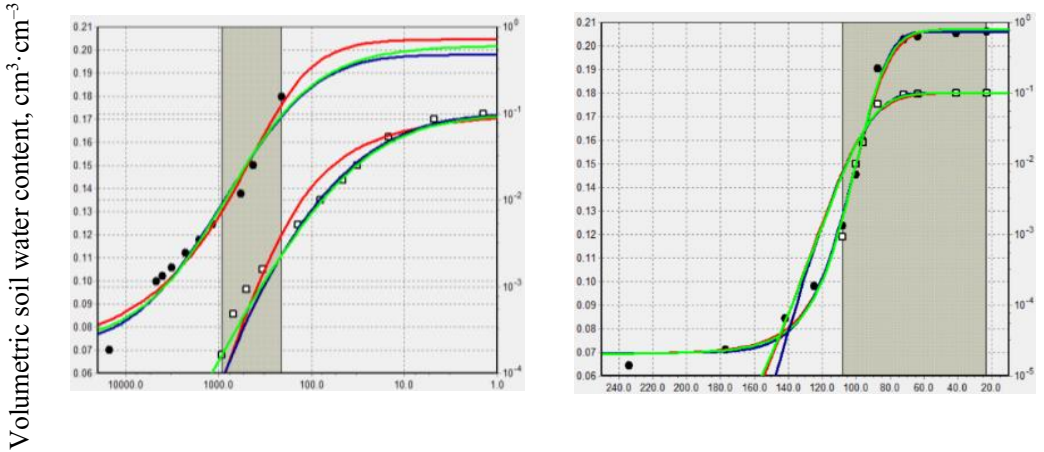

Capillary pressure of moisture (abs. value), $\mathrm{cm} \mathrm{H}_{2} \mathrm{O}$

Fig. 3. «4120 Gilat-fine sand».

Fig. 4. «4131 Berea sandstone».
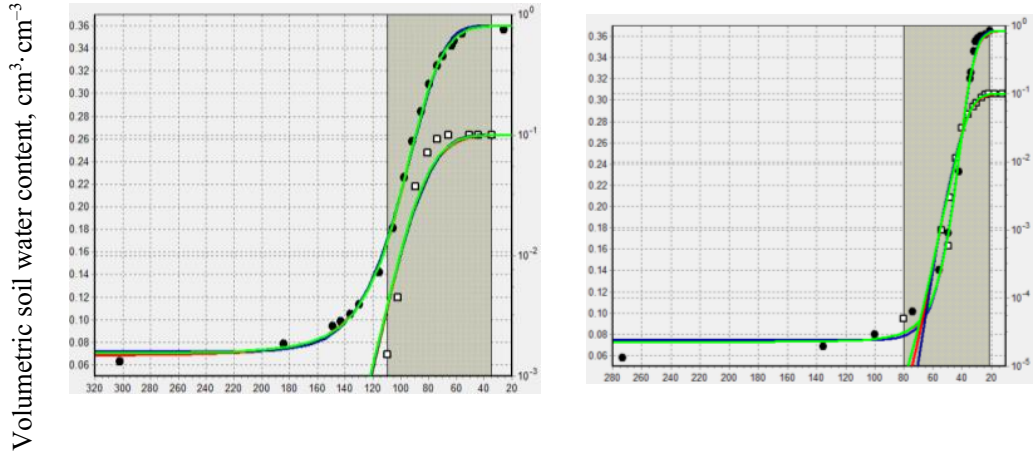

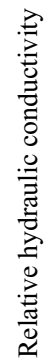

Capillary pressure of moisture (abs. value), $\mathrm{cm} \mathrm{H}_{2} \mathrm{O}$

Fig. 5. «4133 Fine sand (G.E.\#13)».

Fig. 6. «4134 Volcanic sand». 

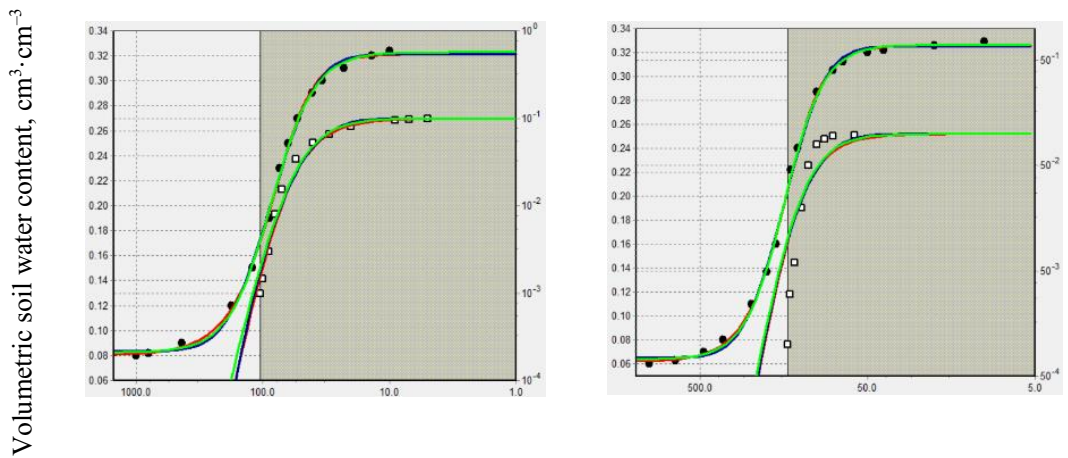

D
0
0
0
0
0
0
0
0
0
0
0
0
0
0

Capillary pressure of moisture (abs. value), $\mathrm{cm} \mathrm{H}_{2} \mathrm{O}$

Fig. 8. «4136 Fine sand G.E.2».

Table 1. Parameters of soil-hydrophysical functions.

\begin{tabular}{|c|c|c|c|c|c|c|}
\hline \multirow[b]{2}{*}{ Soil } & \multirow[b]{2}{*}{$\begin{array}{c}\text { System } \\
\#\end{array}$} & \multicolumn{5}{|c|}{ Parameters } \\
\hline & & $\begin{array}{c}\theta_{S}, \\
\mathrm{~cm}^{3} \cdot \mathrm{cm}^{-3}\end{array}$ & $\begin{array}{c}\theta_{R}, \\
\mathrm{~cm}^{3} \cdot \mathrm{cm}^{-3}\end{array}$ & $\begin{array}{c}\psi_{e} \\
\mathrm{~cm} \mathrm{H}_{2} \mathrm{O}\end{array}$ & $\begin{array}{c}\alpha \\
\mathrm{cm} \mathrm{H}_{2} \mathrm{O}^{-1}\end{array}$ & $n$ \\
\hline \multirow{3}{*}{$\begin{array}{l}1006 \text { Beit } \\
\text { Netofa clay }\end{array}$} & 1 & 0.446 & 0 & - & 0.0015 & 1.17 \\
\hline & 2 & 0.459 & 0.228 & 0 & 0.0004 & 0.835 \\
\hline & 3 & 0.465 & 0.222 & 0 & 0.0004 & 0.803 \\
\hline \multirow{3}{*}{$\begin{array}{l}3405 \text { Indio } \\
\text { loam }\end{array}$} & 1 & 0.467 & 0.033 & - & 0.0060 & 1.814 \\
\hline & 2 & 0.468 & 0.055 & -45.26 & 0.0034 & 1.148 \\
\hline & 3 & 0.472 & 0.052 & -46.47 & 0.0034 & 1.156 \\
\hline \multirow{3}{*}{$\begin{array}{l}4120 \text { Gilat- } \\
\text { fine sand }\end{array}$} & 1 & 0.205 & 0.068 & - & 0.0047 & 1.512 \\
\hline & 2 & 0.198 & 0.072 & 0 & 0.0011 & 0.895 \\
\hline & 3 & 0.202 & 0.072 & 0 & 0.0012 & 0.896 \\
\hline \multirow{3}{*}{$\begin{array}{l}4131 \text { Berea } \\
\text { sandstone }\end{array}$} & 1 & 0.207 & 0.069 & - & 0.0098 & 8.861 \\
\hline & 2 & 0.206 & 0.070 & -23 & 0.0123 & 6.603 \\
\hline & 3 & 0.207 & 0.069 & -23 & 0.0123 & 6.871 \\
\hline \multirow{3}{*}{$\begin{array}{l}4133 \text { Fine } \\
\text { sand } \\
\text { (G.E.\#13) }\end{array}$} & 1 & 0.360 & 0.068 & - & 0.0104 & 6.897 \\
\hline & 2 & 0.360 & 0.072 & 0 & 0.0101 & 6.257 \\
\hline & 3 & 0.360 & 0.071 & -3.56 & 0.0104 & 6.359 \\
\hline \multirow{3}{*}{$\begin{array}{l}4134 \\
\text { Volcanic } \\
\text { sand }\end{array}$} & 1 & 0.365 & 0.073 & - & 0.0230 & 6.758 \\
\hline & 2 & 0.365 & 0.075 & -0.62 & 0.0226 & 6.065 \\
\hline & 3 & 0.365 & 0.073 & -8.38 & 0.0274 & 5.151 \\
\hline \multirow{3}{*}{$\begin{array}{l}4135 \\
\text { Gravelly } \\
\text { sand G.E.9 }\end{array}$} & 1 & 0.321 & 0.080 & - & 0.0144 & 2.961 \\
\hline & 2 & 0.321 & 0.084 & 0 & 0.0117 & 2.481 \\
\hline & 3 & 0.322 & 0.082 & 0 & 0.0117 & 2.559 \\
\hline \multirow{3}{*}{$\begin{array}{l}4136 \text { Fine } \\
\text { sand G.E.2 }\end{array}$} & 1 & 0.326 & 0.062 & - & 0.0071 & 4.060 \\
\hline & 2 & 0.325 & 0.066 & 0 & 0.0064 & 3.571 \\
\hline & 3 & 0.327 & 0.064 & 0 & 0.0064 & 3.700 \\
\hline
\end{tabular}


It can be seen from Table 2 that the errors for all three systems of functions for dot approximation of the measured soil water-retention capacity are commensurable and quite low. Nevertheless, for the prediction of the hydraulic conductivity of unsaturated soils, the results are different. For «4131 Berea sandstone», «4133 Fine sand (GE\#13)», «4134 Volcanic sand», «4135 Gravelly sand G.E.9» and «4136 Fine sand G.E.2» the errors are commensurate for all three systems, but for «1006 Beit Netofa clay», «3405 Indio loam» and «120 Gilat-fine sand» [18], the errors of the system\#1 are noticeably higher than the errors of the systems\#2 and \#3 that are commensurable and quite low. This indicates a more universal character of systems $\# 2$ and \#3. And this is explained by the fact that the functions of systems\#2 and \#3 are physically adequate.

Practical value of the Mualem-Van Genuchten method is obvious: it allows abandoning labor-consuming dimensions of dependence $k(\psi)$. As the results obtained in this paper show, function (2) accurately approximates the experimental data. The derivative of the function (2) is described by a dome-shaped curve, which is characteristic of the differential moisture capacity of the soil. The Mualem-Van Genuchten method allows accurately predicting the relative hydraulic conductivity of unsaturated soils of different granulometric compositions, except for heavy soils, as can be seen from the example of Beit Netofa clay. The reason for the high prediction error of $k / k_{S}$ is in the limitation $n>1$ for function (2) parameter. But the main disadvantage of this method is that the parameters of functions (2), (3) have no physical meaning. For this reason, the prediction $k / k_{S}$ by function (3) is essentially limited by that range of values $\psi$, for which the empirical parameters $\alpha$ and $n$ of function (2) were calculated. In the Figures, this range is highlighted by a darker background.

Table 2. Comparison of the results of dot approximating the measured water-retention capacity and predicting the relative hydraulic conductivity of unsaturated soils with experimental data.

\begin{tabular}{|c|c|c|c|c|c|c|}
\hline \multirow{3}{*}{ Soil } & \multicolumn{6}{|c|}{ RMSE - root mean square error } \\
\hline & \multicolumn{2}{|c|}{ System\#1 } & \multicolumn{2}{|c|}{ System\#2 } & \multicolumn{2}{|c|}{ System\#3 } \\
\hline & WRC-VG & HC-MVG & WRC-K+ & $\mathrm{HC}-\mathrm{MK}+$ & WRC-H+ & HC-MT \\
\hline 1006 Beit Netofa clay & 0.0089 & 0.2769 & 0.0103 & 0.0422 & 0.0104 & 0.0811 \\
\hline 3405 Indio loam & 0.0171 & 0.1018 & 0.0179 & 0.0471 & 0.0180 & 0.0507 \\
\hline 4120 Gilat-fine sand & 0.0056 & 0.0868 & 0.0058 & 0.0412 & 0.0060 & 0.0581 \\
\hline 4131 Berea sandstone & 0.0038 & 0.0848 & 0.0039 & 0.0730 & 0.0038 & 0.0737 \\
\hline $\begin{array}{l}4133 \text { Fine sand } \\
\text { (G.E.\#13) }\end{array}$ & 0.0038 & 0.1455 & 0.0043 & 0.1435 & 0.0039 & 0.1359 \\
\hline 4134 Volcanic sand & 0.0090 & 0.0242 & 0.0092 & 0.0233 & 0.0087 & 0.0240 \\
\hline $\begin{array}{l}4135 \text { Gravelly sand } \\
\text { G.E.9 }\end{array}$ & 0.0038 & 0.0388 & 0.0046 & 0.0474 & 0.0038 & 0.0387 \\
\hline 4136 Fine sand G.E.2 & 0.0033 & 0.1907 & 0.0045 & 0.1830 & 0.0034 & 0.1774 \\
\hline
\end{tabular}

In this article, functions (2) and (3) are contrasted to the functions (4)-(7), forming systems $\# 2$ and \#3. The functions of these two systems are physically adequate, which makes 
it possible to predict $k / k_{S}$ more precisely outside the range of values $\psi$, for which the parameters of these functions were estimated by the method of pointwise approximation of the measured dependence $\theta(\psi)$.

Comparing the systems\#2 и \#3, it should be noted that in the system\#2 a special function $\operatorname{erfc}(x)$ is used. Given the relatively low accuracy of measuring the water-retention capacity and hydraulic conductivity of the soil in currently conducted laboratory studies, the use of special functions for describing these hydrophysical properties is, according to the authors, somewhat redundant. Taking into account that using relations (4), (5) is commensurable with the relations (6), (7) the error of the dot approximation of the measured water-retention capacity and the prediction of the relative hydraulic conductivity of the unsaturated soils of different granulometric compositions, and also that the relations (6), (7) belong to the class of elementary functions and have simpler analytical description. It seems expedient to apply, first of all, the system\#3 in various soil hydrophysical calculations including the search for the solution of differential equations in partial derivatives of a parabolic type, such as the Richards equation [1, 19-24].

\section{Summary}

Three systems of hydrophysical functions can be used in the design, operation or reconstruction of irrigation and drainage systems. The advantage of these systems is that every of them have common parameters. The parameters of system $\# 2$ and $\# 3$ are represented by physical and statistical interpretations.

Comparative analysis of the three systems of hydrophysical functions was carried out using the error criterion of predicting the hydraulic conductivity of unsaturated soil according to data on the water-retention capacity of soil and the moisture filtration coefficient. For the analysis, soils of different granulometric compositions were selected, the data on which were taken from literature.

With regard to the error in the dot approximation of the experimental data on the soil water-retention capacity, all three systems of functions have commensurate and sufficiently low errors. With regard to the prediction of the relative hydraulic conductivity of unsaturated soils, three systems have comparable errors for five soils under study, but for three investigated soils system\#1 has relatively more high errors than the errors of the systems\#2 and \#3 that are comparable. These errors are explained by: i) the formal character of the parameters of the system\#1, which have no physical meaning, and ii) a mathematical restriction on one of the parameters, which significantly narrows the scope of the functions from the system\#1.

From the analysis it follows that the soil-hydrophysical functions from systems\#2 and \#3 have a more universal character, which indicates their physical adequacy and the possibility of use in different hydrophysical calculations.

\section{Acknowledgments}

The research was supported by DAAD (PID: 91619700; A/10/01103) and Russian Foundation for Basic Research (\#16-04-01473-a; \#16-35-00059-mol_a).

\section{References}

1. L.A Richards, Journal of Applied Physics, 1(5), 318-333 (1931).

2. E.V. Shein, Eurasian Soil Science, 48(7), 712-718 (2015). 
3. Y. Mualem, Research Project 442. Technion, Israel Institute of Technology, Haifa, Israel, 100 (1976).

4. Y. Mualem, Water Resources Research, 12, 513-522 (1976).

5. M.Th. Van Genuchten, Soil Science Society of America Journal, 44, 892-989 (1980).

6. W. Brutsaert, Soil Science, 101, 85-92 (1966).

7. L.R. Ahuja, D. Swartzendruber, Soil Science Society of America Proceedings, 36, 9-14 (1972).

8. R. Haverkamp, M. Vauclin, J. Touma, P.J. Wierenga, G. Vachaud, Soil Science Society of America Journal, 41, 285-294 (1977).

9. K. Kosugi, Water Resources Research, 30, 891-901 (1994).

10. K. Kosugi, Water Resources Research, 32, 2697-2703 (1996).

11. V. Terleev, A. Nikonorov, V. Badenko, I. Guseva, Yu. Volkova, O. Skvortsova, S. Pavlov, W. Mirschel, Advances in Civil Engineering, 2016, Article ID 8176728 (2016).

12. V.V. Terleev, W. Mirschel, V.L. Badenko, I.Yu. Guseva, Eurasian Soil Science, 50(4), 445-455 (2017).

13. S. Winitzki, (in https://sites.google.com/site/winitzki/sergei-winitzkis-files/erfapprox.pdf?attredirects $=0$ ) (2008).

14. W. Brutsaert, Advances in Water Resources, 23, 811-815 (2000).

15. K. Kosugi, J.W. Hopmans, Soil Science Society of America Journal, 62, 1496-1505 (1998).

16. K. Kosugi, Soil Science Society of America Journal, 63, 270-277 (1999).

17. V.V. Terleev, A.G. Topazh, W. Mirschel, Russian Meteorology and Hydrology, 40(4), 278-285 (2015).

18. V. Terleev, A. Topaj, K. Moiseev, R. Ginevsky, V. Lazarev, Agrophysics, 2, 52-61 (2018) (in Russian).

19. A. Nikonorov, V. Terleev, S. Pavlov, I. Togo, Y. Volkova, T. Makarova, V. Garmanov, D. Shishov, W. Mirschel, Procedia Engineering, 165, 1741-1747 (2016).

20. A. Nikonorov, V. Terleev, V. Badenko, W. Mirschel, E. Abakumov, et.al., IOP Conference Series: Earth and Environmental Science, 90, Article ID 012109 (2017)

21. S. Medvedev, A. Topaj, V. Badenko, V. Terleev, IFIP Advances in Information and Communication Technology, 448, 252-261 (2015).

22. V. Badenko, N. Badenko, A. Nikonorov, D. Molodtsov, V. Terleev, J. Lednova, V. Maslikov, MATEC Web of Conferences, 73, Article ID 03003 (2016).

23. V.V. Terleev, A.O Nikonorov, I. Togo, Yu.V. Volkova, et.al. Magazine of Civil Engineering, 70(2), 84-92 (2017).

24. V.V. Terleev, A.O Nikonorov, R.S. Ginevsky, V.A. Lazarev, I. Togo, et.al., Magazine of Civil Engineering, 77(1), 141-148 (2018). 